\title{
JUDD OFELT ANALYSIS AND OPTICAL PROPERTIES OF RARE EARTH DOPED TELLURITE GLASSES
}

\author{
TRAN THI HONG \\ Da Nang University of Education, \\ 459 Ton Duc Thang Road, Da Nang, Vietnam \\ PHAN TIEN DUNG \\ Institute of Materials Science, Vietnam Academy of Science and Technology, \\ 18 Hoang Quoc Viet Road, Cau Giay, Hanoi, Vietnam \\ VU XUAN QUANG \\ Duy Tan University, K7/25 Quang Trung Road, Da Nang, Vietnam \\ Received 19 November 2013 \\ Accepted for publication 31 December 2013
}

\begin{abstract}
In this work, the structural characteristic and photoluminescence properties were investigated in $\mathrm{Eu}^{3+}$ ions-doped $\mathrm{B}_{2} \mathrm{O}_{3}-\mathrm{TeO}_{2}-\mathrm{ZnO}-\mathrm{Na}_{2} \mathrm{O}$ glasses. These glasses were prepared by the melting method in air, after that thermal annealed $350^{\circ} \mathrm{C}, 450^{\circ} \mathrm{C}$ and $550^{\circ} \mathrm{C}$ for different times. The analysis results of structure on these glasses showed the formation of micro-crystals in host glass after thermal annealed process. The photoluminescence spectra of Eu ${ }^{3+}$ ions in these samples were observed. The local vibration mode around $\mathrm{Eu}^{3+}$ ions was investigated by the phonon side band associated with ${ }^{7} F_{0}-{ }^{5} D_{2}$ transition of $E u^{3+}$. Judd-Ofelt parameters have been evaluated from photoluminescence spectra and were to predict the luminescence intensity ratios of ${ }^{5} D_{0} \rightarrow{ }^{7} F_{J}$ $(J=2,4$ and 6$)$ to ${ }^{5} D_{0} \rightarrow{ }^{7} F_{1}$ transition. The obtained results have been used for calculating $\Omega_{2}$, $\Omega_{4}, \Omega_{6}$ parameters by using Judd-Ofelt theory. These $\Omega_{2}, \Omega_{4}, \Omega_{6}$ parameters allow to derive radiative properties of $\mathrm{Eu}^{3+}$ ions in glass material such as transition probabilities, radiative lifetimes and peak stimulated emission cross-section for the ${ }^{5} D_{0} \rightarrow{ }^{7} F_{J}$ transitions.
\end{abstract}

\section{INTRODUCTION}

Oxide glasses are the most stable host matrices for practical applications due to their high chemical durability and thermal stability. Among the oxide glasses, tellurite glasses have proved to be interesting host for lanthanide ions, both from a fundamental and an applied point of view. It is well-known, the non-radiative loss is dominated by the highest energy phonon available in the matrix. Therefore, it is meaningful to select a host material for which the maximum phonon energy is as low as possible. In silica, this phonon energy is reasonably large (about $1100 \mathrm{~cm}^{-1}$ ). It is quite low for chalcogenide glasses (about $300 \mathrm{~cm}^{-1}$ ), which, however, lack many of the desirable features of silica-based glasses, including mechanical strength and chemical durability. Tellurite glasses represent a compromise between the desire for a low phonon energy $\left(650-750 \mathrm{~cm}^{-1}\right)[1-3]$ host 
couple with the need to retain mechanical strength and process temperatures... However, less spectroscopic study on Borate-tellurite-zinc-sodium based glass was reported.

Among the $\mathrm{Ln}^{3+}$ ions used to optically activate the glass matrices, the trivalent europium ion $\mathrm{Eu}^{3+}$ is the mostly used choice due to the fact that $\mathrm{Eu}^{3+}\left(4 \mathrm{f}^{6}\right)$ ions emit narrow band, almost monochromatic light and have long lifetimes of the optically active states. $\mathrm{Eu}^{3+}$ is usually the rare earth ion of choice for several studies due to its simple electronic energy level scheme. $\mathrm{Eu}^{3+}$ ions exhibit pure magnetic and electric dipole transitions which make it a very sensitive probe for the rare earth ion site structure symmetry. The transition probability of hypersensitive transition $\left({ }^{5} \mathrm{D}_{0} \rightarrow{ }^{7} \mathrm{~F}_{2}\right)$ of $\mathrm{Eu}^{3+}$ ion is depressed under higher symmetric environment whereas the magnetic dipole transition are not affected by the environment and their emission intensities are often used as internal standard $[4,5]$.

\section{EXPERIMENTS}

Using the melting method, $40 \mathrm{~B}_{2} \mathrm{O}_{3} .40 \mathrm{TeO}_{2}$. $10 \mathrm{ZnO} .10 \mathrm{Na}_{2} \mathrm{O}$ glasses containing $\mathrm{Eu}_{2} \mathrm{O}_{3} 1 \mathrm{~mol} \%$ concentrations were prepared with two process (melting and heatedtreatment). The starting components $\mathrm{B}_{2} \mathrm{O}_{3}, \mathrm{TeO}_{2}, \mathrm{ZnO}, \mathrm{Na}_{2} \mathrm{CO}_{3}$ and $\mathrm{Eu}_{2} \mathrm{O}_{3}$ were used. At first, the all components were mixed and dried at $100^{\circ} \mathrm{C}$ for $3 \mathrm{~h}$. After that the mixture was melted at $1200^{\circ} \mathrm{C}$ in air for $2 \mathrm{~h}$ in a $\mathrm{Pt}$ crucible. The fining temperature was 1150 ${ }^{\circ} \mathrm{C}$ for about $15 \mathrm{~min}$. The glass samples was obtained by cooling the melt down to room teperature slowly. Then, the glasses was heated-treatment in oven at $350^{\circ} \mathrm{C}, 450^{\circ} \mathrm{C}$ and $550^{\circ} \mathrm{C}$ for $10 \mathrm{~h}, 15 \mathrm{~h}$ and $24 \mathrm{~h}$, respectively. The resulting glass, which was transparent colorless. Followed, the sample was cut and polished for optical measurements.

$\mathrm{X}$-ray diffraction measurement by on a XRD-D5000 SIEMENS diffractometer. Excitation and emissition spectra of the samples were measured using Horiba FluoroLog Spectrophotometer FL3-22 using a 450W xenon lamp source, monochromator (f/3.6 CzenyTurner, double grating, all reflective optics) and R928P photomultiplier and recorded under computer control software FluorEssence 2.0 (powered by Origin 7.5). All the measurements were carried out at room temperature.

\section{RESULTS AND DISCUSSION}

\section{III.1. Structural characterization}

Generally, melting is a strongly method to prepare the glass materials. Beside, heated-treatment for as-prepared glasses is an important process which produce stable structure of glass. During this process, the micro-crystals can be formed in host glass which is called glass-ceramic materials.

To identify crystallization phase, XRD analysis was performed on a X-ray powder diffractometer (XRD-D5000) with $\mathrm{CuK} \alpha$ radiation. The XRD spectra of glass samples are compared in Fig, 1a-c in the range of $2 \theta=20^{\circ}$ to $70^{\circ}$. Show the XRD diagram of the glass samples heated-treatment at $350^{\circ} \mathrm{C}-10 \mathrm{~h}$ (a), $450^{\circ} \mathrm{C}-15 \mathrm{~h}$ (b) and $550^{\circ} \mathrm{C}-24 \mathrm{~h}$ (c). The structural analysis results exhibit that the amorphous phases of the glass sample heatedtreatment $350^{\circ} \mathrm{C}-10 \mathrm{~h}$, while the heated sample at $450^{\circ} \mathrm{C}-15 \mathrm{~h}$ and $550^{\circ} \mathrm{C}-24 \mathrm{~h}$ exhibits both amorphous and crystaline phase. As we know, the glass crystallization process strongly 


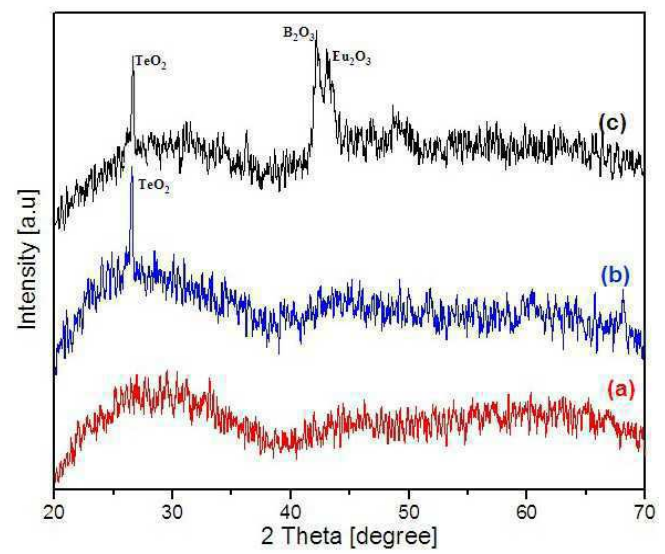

Fig. 1. XRD patterns of $1 \mathrm{~mol} \% \mathrm{Eu}^{3+}$ doped $40 \mathrm{~B}_{2} \mathrm{O}_{3} \cdot 40 \mathrm{TeO}_{2} \cdot 10 \mathrm{ZnO} \cdot 10 \mathrm{Na}_{2} \mathrm{O}$ glass samples heat-treatment $350^{\circ} \mathrm{C}-10 \mathrm{~h}(\mathrm{a}), 450^{\circ} \mathrm{C}-15 \mathrm{~h}(\mathrm{~b})$ and $550^{\circ} \mathrm{C}-24 \mathrm{~h}(\mathrm{c})$

depend on the conditions of thermal annealing as temperature, time and host components. Therefore, these initial result suggest to allow preparation glass-ceramic materials $[6,7]$.

\section{III.2. Optical properties}

\section{A. Excitation spectrum}

The excitation spectrum for $612 \mathrm{~nm}$ red emission of $1 \mathrm{~mol} \% \mathrm{Eu}^{3+}$ doped the samples is shown in Fig. 2. The transitions of excitation spectra are assigned (originating from ${ }^{7} \mathrm{~F}_{0}$ and ${ }^{7} \mathrm{~F}_{1}$ ) based on free-ion energy level structure and by taking into account both the electric and magnetic dipole contributions. There are fifteen obvious excitation peaks parking at $299 \mathrm{~nm}, 304 \mathrm{~nm}, 319 \mathrm{~nm}, 327 \mathrm{~nm}, 361 \mathrm{~nm}, 365 \mathrm{~nm}, 377 \mathrm{~nm}, 382 \mathrm{~nm}, 394 \mathrm{~nm}$, $400 \mathrm{~nm}, 414 \mathrm{~nm}, 465 \mathrm{~nm}, 472 \mathrm{~nm}, 526 \mathrm{~nm}, 533 \mathrm{~nm}$. Among them the intensities of $394 \mathrm{~nm}$ excitation peak is strongest.

The PSB of the ${ }^{5} \mathrm{D}_{2}-{ }^{7} \mathrm{~F}_{0}$ transition of the $\mathrm{Eu}^{3+}$ ion was observed in the excition spectrum as shown in Fig.2. The PSB of the $\mathrm{B}_{2} \mathrm{O}_{3}$ - base glass is due to the stretching vibration modes of $\mathrm{B}_{-} \mathrm{O}^{-}$and $\mathrm{B}-\mathrm{O}$ of $\mathrm{B}_{2} \mathrm{O}_{3}$ and $\mathrm{BO}_{4}^{-}$units in tetra-and diborate groups [8], where $-\mathrm{O}^{-}$and $-\mathrm{O}$ stand for the non-bridging oxygen (NBO) and bridging oxygen (BO), respectively. In fact, PSB is influenced both by the stretching vibration mode of NBO in the neighborhood of the $\mathrm{Eu}^{3+}$ ion and by the stretching vibration modes of $\mathrm{NBO}$ and $\mathrm{BO}$ which are apart from the $\mathrm{Eu}^{3+}$ ion.

The energy level diagram (Fig. 3) of $\mathrm{Eu}^{3+}$ shows the energy gaps among the levels of ${ }^{5} \mathrm{G}_{2},{ }^{5} \mathrm{~L}_{6},{ }^{5} \mathrm{D}_{3},{ }^{5} \mathrm{D}_{2},{ }^{5} \mathrm{D}_{1}$ and ${ }^{5} \mathrm{D}_{0}$. The emision efficiencies of ${ }^{5} \mathrm{D}_{3},{ }^{5} \mathrm{D}_{2}$ and ${ }^{5} \mathrm{D}_{1}$ levels are related with the non-radiative rates $\mathrm{W}_{N R}$ tightly. $\mathrm{W}_{N R}$ can be expressed by:

$$
\mathrm{W}_{N R}=\mathrm{W}_{P}+\mathrm{W}_{E T}
$$

Where $\mathrm{W}_{P}$ is the multiphonon decay rate and $\mathrm{W}_{E T}$ is the relaxation rate by energy transfer. For the lower concentration of $\mathrm{Eu}^{3+}$ doping, the contribution of $\mathrm{W}_{E T}$ can be ignored temporally, and the factor dominating the quantum efficiency is $\mathrm{W}_{P}$, which is 


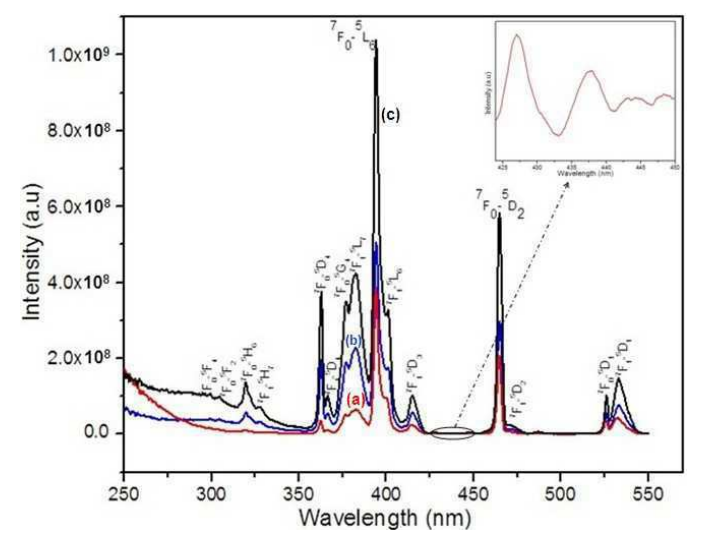

Fig. 2. Room temperature excitation spectrum $\left(\lambda_{e m}=612 \mathrm{~nm}\right)$ of $1 \mathrm{~mol} \% \mathrm{Eu}^{3+}$ doped $40 \mathrm{~B}_{2} \mathrm{O}_{3} \cdot 40 \mathrm{TeO}_{2} \cdot 10 \mathrm{ZnO} .10 \mathrm{Na}_{2} \mathrm{O}$ glass samples heat-treatment at $350^{\circ} \mathrm{C}$ $10 \mathrm{~h}(\mathrm{a}), 450^{\circ} \mathrm{C}-15 \mathrm{~h}(\mathrm{~b})$ and $550^{\circ} \mathrm{C}-24 \mathrm{~h}(\mathrm{c})$.

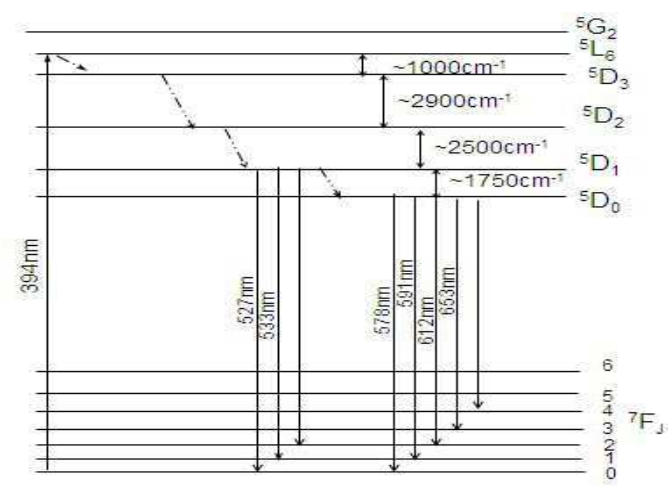

Fig. 3. Energy level diagram of $\mathrm{Eu}^{3+}$ in $\mathrm{B}_{2} \mathrm{O}_{3}-\mathrm{TeO}_{2}-\mathrm{ZnO}-\mathrm{Na}_{2} \mathrm{O}$ glasses.

associated with the phonon energy, $W_{P}$ is expressed by

$$
\mathrm{W}_{P}=\mathrm{W}_{0} \exp \left(\frac{-\alpha \Delta E}{\hbar \omega}\right)
$$

Where $\Delta E$ is the energy gap to the next lower level and is the phonon energy of the matrix glass. $\mathrm{W}_{0}$ is transition probability extrapolated to zero energy gap, which is independent of the electronic nature of the $\mathrm{RE}$ ion. $\alpha=\ln [\Delta E /(\hbar \omega g)] o$, where $\mathrm{g}$ is the electron phonon coupling strength [9]. According to Eq. (2), $\mathrm{W}_{N R}$ should be much larger in silicate and phosphate with higher maximum-phonon energies $\left(\hbar \omega \sim 1100 \mathrm{~cm}^{-1}\right.$ and $\sim 1300 \mathrm{~cm}^{-1}$, respectively) than in tellurite glass $\left(\hbar \omega \sim 750 \mathrm{~cm}^{-1}\right)$ and it is the main reason why the emissions of $\mathrm{Eu}^{3+}$ from ${ }^{5} \mathrm{D}_{3},{ }^{5} \mathrm{D}_{2}$ and ${ }^{5} \mathrm{D}_{1}$ levels could not be observed in silicate and phosphate glasses but can be recorded in tellurite $\left(40 \mathrm{~B}_{2} \mathrm{O}_{3} .40 \mathrm{TeO}_{2} \cdot 10 \mathrm{ZnO}\right.$. $10 \mathrm{Na}_{2} \mathrm{O} .1 \mathrm{Eu}^{3+}$ ) glasses clearly. 


\section{B. Emission spectrum}

The emission spectrum of $1 \mathrm{~mol} \% \mathrm{Eu}^{3+}$ doped the samples in Fig. 4 which were obtained by exciting in the ${ }^{5} \mathrm{~L}_{6}$ state using a $394 \mathrm{~nm}$ wavelength of broad band Xenon lamp source. Emission is mainly observed for ${ }^{5} \mathrm{D}_{0} \quad \rightarrow{ }^{7} \mathrm{~F}_{J}(\mathrm{~J}=0,1,2,3,4)$ transitions (with maximums at $578 \mathrm{~nm} ; 591 \mathrm{~nm} ; 612 \mathrm{~nm} ; 653 \mathrm{~nm}$ and $700 \mathrm{~nm}$, respectively) and a weak emission is noticed for ${ }^{5} \mathrm{D}_{1} \rightarrow{ }^{7} \mathrm{~F}_{0,1,2}$ (with maximums at $527 \mathrm{~nm} ; 534 \mathrm{~nm} ; 553 \mathrm{~nm}$, respectively) which are assigned Fig.4. when increasing the temperature heat- treatment, the intensity spectrum increase significantly.

The emission intensity of ${ }^{5} \mathrm{D}_{0} \rightarrow{ }^{7} \mathrm{~F}_{2,4}$ transitions are induced electric dipole allowed and depend strongly on the local symmetry around $\mathrm{Eu}^{3+}$ ion. Moreover, the ${ }^{5} \mathrm{D}_{0} \rightarrow{ }^{7} \mathrm{~F}_{2}$ is said to be hypersensitive transition (under the selection rule $\Delta \mathrm{J}=2$ ) to the surrounding environment, where as the transition ${ }^{5} \mathrm{D}_{0} \rightarrow{ }^{7} \mathrm{~F}_{1}$ is magnetic dipole allowed and is independent of the local symmetry.

Therefore, the ratio of intergrated emission intensity of the ${ }^{5} \mathrm{D}_{0} \rightarrow{ }^{7} \mathrm{~F}_{2}$ transition to that of the ${ }^{5} \mathrm{D}_{0} \rightarrow{ }^{7} \mathrm{~F}_{1}$ transition, defined as fluorescence intensity ratio $\mathrm{R}$, is the spectroscopic key to estimate the deviation from the site symmetry of the $\mathrm{Eu}^{3+}$ ions. Sometime, $R$ is defined also as asymmetry ratio. In our experiments, the emission spectra are recorded for the sample $40 \mathrm{~B}_{2} \mathrm{O}_{3}$. $40 \mathrm{TeO}_{2}$. $10 \mathrm{ZnO} .10 \mathrm{Na}_{2} \mathrm{O} .1 \mathrm{Eu}_{2} \mathrm{O}_{3}$ excited by the wavelength $394 \mathrm{~nm}$. The fluorescence intensity ratio $\mathrm{R}$ receives the value of $4.1 ; 3.9$ and 3.8 which are given the glass samples heated-treatment at $350^{\circ} \mathrm{C}-10 \mathrm{~h} ; 450^{\circ} \mathrm{C}-15 \mathrm{~h}$ and $550^{\circ} \mathrm{C}-24 \mathrm{~h}$, respectively. From Kumar et al. [10], most of the $\mathrm{Eu}^{3+}$ doped glasses exhibit the $\mathrm{R}$ in the range of 3. 5-4. 2. This indicates the potential of borate-tellurite-zinc-sodium: $\mathrm{Eu}^{3+}$ glass as a laser and red luminescence material.

\section{III.3. Judd- Ofelt analysis}

The Judd-Ofelt theory was often used to calculate the intensity parameters $\Omega_{\lambda}$ $(\lambda=2,4,6)$. The intensity parameters $\Omega_{\lambda}$ could be obtained from absorption spectra. But sometimes the measurement of absorption spectra is difficult. However, the strong luminescence is a characteristic feature for many europium doped materials [11]. Therefore, the Judd-Ofelt analysis by emission spectra is frequently used for the $\mathrm{Eu}^{3+}$ doped host matrices.

The emission spectrum of Borate-tellurite-zinc-sodium: $\mathrm{Eu}^{3+}$ ion excited by $394 \mathrm{~nm}$ light is shown in Fig. 4. Three main emission peaks ${ }^{5} \mathrm{D}_{0} \rightarrow{ }^{7} \mathrm{~F}_{1} ;{ }^{5} \mathrm{D}_{0} \rightarrow{ }^{7} \mathrm{~F}_{2} ;{ }^{5} \mathrm{D}_{0} \rightarrow{ }^{7} \mathrm{~F}_{4}$ are used to calculate the J.O parameters.

The ${ }^{5} \mathrm{D}_{0} \rightarrow{ }^{7} \mathrm{~F}_{1}$ is magnetic dipole transition and its spontaneous emission probability $\mathrm{A}_{m d}$ is given using the following expression [4,5]:

$$
A_{m d}=\frac{64 \pi^{4}}{3 h} \frac{\nu^{3}}{2 J+1} n^{3} S_{m d}
$$

where $\nu$ is the wave number of transition, $h$ is the Planck constant, $J$ is the total angle momentum of the excited state, $\mathrm{n}$ is the refractive index, $S_{m d}$ is the magnetic-dipole line strength, which is a constant and independent from the host material. 


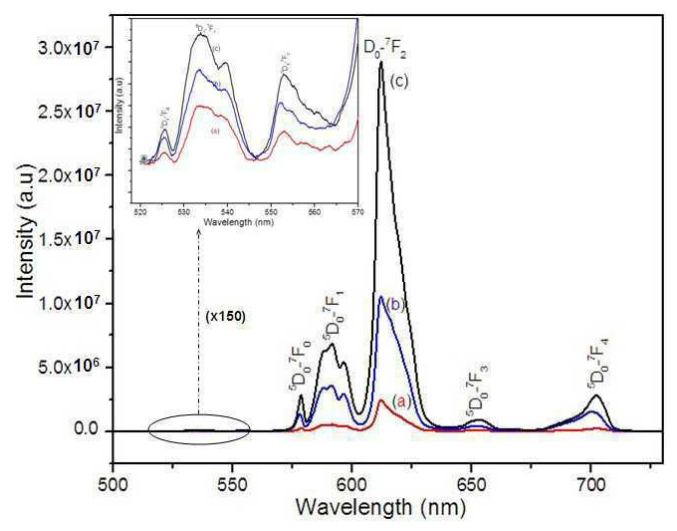

Fig. 4. Room temperature emission spectrum $\left(\lambda_{e x}=394 \mathrm{~nm}\right)$ of $1 \mathrm{~mol} \% \mathrm{Eu}^{3+}$ doped $40 \mathrm{~B}_{2} \mathrm{O}_{3} .40 \mathrm{TeO}_{2} .10 \mathrm{ZnO} .10 \mathrm{Na}_{2} \mathrm{O}$ glass samples with heat-treatments $350^{\circ} \mathrm{C}$ $10 \mathrm{~h}(\mathrm{a}), 450^{\circ} \mathrm{C}-15 \mathrm{~h}(\mathrm{~b})$ and $550^{\circ} \mathrm{C}-24 \mathrm{~h}(\mathrm{c})$

The value of $A_{m d}$ can be estimated using the reference value of $A_{m d}^{\prime}$ published somewhere and using the relationship $A_{m d}=\left(\mathrm{n} / \mathrm{n}^{\prime}\right)^{3} A_{m d}^{\prime}$; where $A_{m d}^{\prime}$ and $n^{\prime}$ are spontaneous emission probability and refractive index of the reference material. For example, with the value of $A_{m d}^{\prime}$ of lithium fluoroborate glass doped by mol $1 \% \mathrm{Eu}^{3+}$ is $51.9 \mathrm{~s}^{-1}$, $n^{\prime}=1.539[12]$.

The ${ }^{5} \mathrm{D}_{0} \rightarrow{ }^{7} \mathrm{~F}_{J=2,4,6}$ transitions are electronic dipole allowed. The spontaneous emission probabilities $A_{e d}$ of electronic transition is given using the following expression:

$$
A_{e d}=\frac{64 \pi^{4} e}{3 h} \frac{\nu_{J}^{3}}{2 J^{\prime}+1} \frac{n\left(n^{2}+2\right)^{2}}{9} S_{e d}
$$

where $\nu_{J}$ is the wave number of transition ${ }^{5} \mathrm{D}_{0} \rightarrow{ }^{7} \mathrm{~F}_{J} ; e$ is the electron charge; $h$ is Planck constant; $n$ is the refractive index; $J^{\prime}$ is the total angle momentum of excited state; $\mathrm{S}_{e d}$ is the electric-dipole line strength of the transition [13].

The emission intensity $\mathrm{I}$ of a given transition is proportional to the area $\mathrm{S}$ under the emission curve: $\mathrm{I}=\mathrm{h} \nu \mathrm{A}_{r} \mathrm{~N} \alpha \mathrm{S}$. Where $\mathrm{h} \nu$ is transition energy, $\mathrm{A}_{r}$ is radioactive transition rate, $\mathrm{N}$ is population of emitting level $\left({ }^{5} \mathrm{D}_{0}\right)$. Thus, the $\Omega_{\lambda}$ parameters could be evaluated simply by the ratio of the intensity of the ${ }^{5} \mathrm{D}_{0} \rightarrow{ }^{7} \mathrm{~F}_{J=2,4,6}$ transitions to the intensity of ${ }^{5} \mathrm{D}_{0} \rightarrow{ }^{7} \mathrm{~F}_{1}$ transition as follow:

$$
\frac{\int I_{J} d \nu}{\int I_{1} d \nu}=\frac{A_{J}}{A_{1}}=\frac{e^{2}}{S_{m d 1}} \frac{\nu_{J}^{3}}{\nu_{1}^{3}} \frac{n\left(n^{2}+2\right)^{2}}{9 n^{3}} \Omega_{J}\left\|U^{J}\right\|^{2}
$$

As seen from Eq. (5), the $\Omega_{2}$ and $\Omega_{4}$ can be evaluated independently from the emission transitions of ${ }^{5} \mathrm{D}_{0} \rightarrow{ }^{7} \mathrm{~F}_{2}$ and ${ }^{5} \mathrm{D}_{0} \rightarrow{ }^{7} \mathrm{~F}_{4}$. The $\Omega_{6}$ can not be evaluated because of limitation of our experimental condition. Since the emission transition ${ }^{5} \mathrm{D}_{0} \rightarrow{ }^{7} \mathrm{~F}_{6}$ at about $810 \mathrm{~nm}$ has not been observed from the emission spectra, the $\Omega_{6}$ parameter could not be determined in our experiment. Because the ${ }^{5} \mathrm{D}_{0} \rightarrow{ }^{7} \mathrm{~F}_{6}$ emission intensity is usually very weak compared with the intensities of the of ${ }^{5} \mathrm{D}_{0} \rightarrow{ }^{7} \mathrm{~F}_{2}$ and ${ }^{5} \mathrm{D}_{0} \rightarrow{ }^{7} \mathrm{~F}_{4}$ transitions. The calculated $\Omega_{2}$ and $\Omega_{4}$ parameters are presented in Table 1 . 
Table 1. Judd-Ofelt parameters $\left(\Omega_{\lambda} \times 10^{-20} \mathrm{~cm}^{2}\right)$

\begin{tabular}{|l|l|l|l|}
\hline$\Omega_{\lambda}$ & $\begin{array}{l}\text { The sample } \\
\left(350^{0}-10 \mathrm{~h}\right)\end{array}$ & $\begin{array}{l}\text { The sample } \\
\left(450^{\circ} \mathrm{C}-15 \mathrm{~h}\right)\end{array}$ & $\begin{array}{l}\text { The sample } \\
\left(550^{\circ} \mathrm{C}-24 \mathrm{~h}\right)\end{array}$ \\
\hline$\Omega_{2}$ & 4,872 & 4,718 & 4,614 \\
$\Omega_{4}$ & 1,463 & 1,487 & 1,519 \\
$\Omega_{6}$ & - & - & - \\
\hline
\end{tabular}

From Table 1 , the $\Omega_{2}$ value is greater than $\Omega_{4}$ and the value of $\Omega_{6}$ can not be evaluated in each of samples. Thus, it can conclude that the radiative transition probabilities are mainly dependent on the ${ }^{5} \mathrm{D}_{0} \rightarrow{ }^{7} \mathrm{~F}_{2}$ red hypersensitive emission transition. This result is in agreement with that of the other tellurite glasses [14].

According to Refs. $[15,16]$ the fluorescence intensity ratio $(\mathrm{R})$ of ${ }^{5} \mathrm{D}_{0} \rightarrow{ }^{7} \mathrm{~F}_{2}$ to ${ }^{5} \mathrm{D}_{0} \rightarrow{ }^{7} \mathrm{~F}_{1}$ transitions is used to establish the degree of asymmetry in the vicinity of $\mathrm{Eu}^{3+}$ ions and Eu-O covalence. Moreover, the $\mathrm{R}$ value also depends on the JO parameter $\Omega_{2}$, which is used to explain the short-range effects. Therefore, the variation of $\mathrm{R}$ and in turn $\Omega_{2}$ gives the information about the short range effect on local structure around $\mathrm{Eu}^{3+}$ ions and $\mathrm{Eu}-\mathrm{O}$ covalent. The higher the value of $\mathrm{R}$, the lower the symmetry around the $\mathrm{Eu}^{3+}$ ions and the higher the Eu-O covalent. In table 1, the increase of the heat-treated temperature, the $\mathrm{R}$ values and $\Omega_{2}$ decrease significantly, but $\Omega_{4}$ increase significantly. When the increase of the heat-treated temperature, the degree of symmetry in the vicinity of $\mathrm{Eu}^{3+}$ ions increase and rigidity increase.

The Judd-Ofelt theory parameters no only can give the information on local structure and binding state of RE -ions in host matrices, but from the parameters $\Omega_{\lambda}$, several important optical properties such as branching ratio, relative transition probabilities, life time of the excited states... could be evaluated. The radiative transition probability for transition $\psi \mathrm{J} \rightarrow \psi^{\prime} \mathrm{J}$ ' is given by: $\mathrm{A}\left(\psi \mathrm{J} \rightarrow \psi^{\prime} \cdot \mathrm{J}^{\prime}\right)=\mathrm{A}_{e d}+\mathrm{A}_{m d}$

The calculated radiative life time $\tau_{\text {cal }}$ of the excited state can be obtained from $\mathrm{A}_{\text {total }}: \mathrm{A}_{\text {total }}(\psi \mathrm{J})=\sum_{\Psi^{\prime} J^{\prime}} A\left(\psi \mathrm{J}, \psi^{\prime} \mathrm{J}^{\prime}\right)=1 / \tau_{\text {cal }}$ such in order to receive $\tau_{\text {cal }}$ of ${ }^{5} \mathrm{D}_{0}$ state, it is necessary to evaluate the radiative transition probability of the ${ }^{5} \mathrm{D}_{0} \rightarrow{ }^{7} \mathrm{~F}_{1},{ }^{5} \mathrm{D}_{0} \rightarrow{ }^{7} \mathrm{~F}_{2}$ and ${ }^{5} \mathrm{D}_{0} \rightarrow{ }^{7} \mathrm{~F}_{4}$ transitions. Because the value of the reduced matrix small, the ${ }^{5} \mathrm{D}_{0} \rightarrow{ }^{7} \mathrm{~F}_{6}$ is negligible, the $\mathrm{A}_{e d}$ of this transition can be negligible in $\tau_{c a l}$. The branching ratio is given: $\beta_{R}\left(\psi \mathrm{J}, \psi^{\prime} \mathrm{J} '\right)=\mathrm{A}\left(\psi \mathrm{J}, \psi^{\prime} \mathrm{J}{ }^{\prime}\right) / \mathrm{A}_{\text {tota }} \mathrm{l}(\psi \mathrm{J})$.

Table 2. The branching ratio $\beta_{R}\left({ }^{5} \mathrm{D}_{0} \rightarrow{ }^{7} \mathrm{~F}_{2}\right)(\%)$, the life time of the excited $\tau_{c a l}$ and $\tau_{\text {exp }}$ of samples

\begin{tabular}{llll}
\hline \hline & $\begin{array}{l}\text { The sample } \\
\left(350^{0}-10 \mathrm{~h}\right)\end{array}$ & $\begin{array}{l}\text { The sample } \\
\left(450^{\circ} \mathrm{C}-15 \mathrm{~h}\right)\end{array}$ & $\begin{array}{l}\text { The sample } \\
\left(550^{\circ} \mathrm{C}-24 \mathrm{~h}\right)\end{array}$ \\
\hline \hline$\tau_{\text {cal }}(\mathrm{ms})$ & 2,984 & 3,118 & 3,269 \\
$\tau_{\exp }(\mathrm{ms})$ & 1,181 & 1,235 & 1,244 \\
$\beta_{R}\left({ }^{5} \mathrm{D}_{0} \rightarrow{ }^{7} \mathrm{~F}_{2}\right)(\%)$ & 72,56 & 73,32 & 75,14 \\
\hline \hline
\end{tabular}


The life time $\tau_{\text {cal }}$ of the excited state $\left({ }^{5} \mathrm{D}_{0}\right)$ of this Borate-tellurite-zinc-sodium is longer than the experimental life time $\tau_{\text {exp }}$. This is perfectly reasonable, the experimental life time $\left(\tau_{\exp }\right)$ is always the contribution of both conversion: emission and non- emission. Meanwhile, the life time $\left(\tau_{c a l}\right)$ is only emission.

\section{CONCLUSION}

$\mathrm{Eu}^{3+}$ doped $40 \mathrm{~B}_{2} \mathrm{O}_{3} \cdot 40 \mathrm{TeO}_{2} \cdot 10 \mathrm{ZnO} \cdot 10 \mathrm{Na}_{2} \mathrm{O}$ glasses with $1 \mathrm{~mol} \%$ has been studied. Crystalline phase is formed in dominated amorphous phase for heated glass (at $450^{\circ} \mathrm{C}$ $15 \mathrm{~h}$ and $550^{\circ} \mathrm{C}-24 \mathrm{~h}$ ). Heat treatment for longer of time is a good condition for glass crystallization process, produces micro-crystals in host glass. The emission and excitation spectra of $\mathrm{Eu}^{3+}$ ions in these samples were observed. The PSB of the ${ }^{5} \mathrm{D}_{2}-{ }^{7} \mathrm{~F}_{0}$ transition of the $\mathrm{Eu}^{3+}$ ion was observed in the excitation spectrum. From the emission spectra, the obtained results have been used for calculating $\Omega_{2}, \Omega_{4}$ parameters by using JuddOfelt theory. A relatively higher value of $\Omega_{2}$ could be related with higher asymmetry around $\mathrm{Eu}^{3+}$ ions in this non-linear optical material. The $\Omega_{2}$ value is greater than $\Omega_{4}$ and the value of $\Omega_{6}$ is negligible in this material. Thus, it can be concluded that the radiative transition probabilities are mainly dependent on the ${ }^{5} \mathrm{D}_{0} \rightarrow{ }^{7} \mathrm{~F}_{2}$ red hypersensitive emission transition. Radiative properties for the ${ }^{5} \mathrm{D}_{0}$ level of $\mathrm{Eu}^{3+}$ ions can be predicted by assuming ${ }^{5} \mathrm{D}_{0} \rightarrow{ }^{7} \mathrm{~F}_{6}$ is negligible. The high brightness and short lifetime of ${ }^{5} \mathrm{D}_{0} \rightarrow{ }^{7} \mathrm{~F}_{2}$ emission show the good potential application of Borate-tellurite-zinc-sodium glass in photonics.

\section{ACKNOWLEDGMENT}

The authors gratefully acknowledge financial support for this research from Danang University of Education and the University of Danang.

\section{REFERENCES}

[1] A. Hishikawa, H. Hasegawa, and K. Yamanouchi, J. Electron Spectrosc. Relat. Phenom. 141 (2004) 195-200.

[2] C.Joshi, R.N.Rai, and S.B.Rai, Journal of quantitative Spectroscopy $\& 5$ Radiative Transfer 113 (2012) 397-404.

[3] M. Clara Goncalves, Luis F. Santos, and Rui M. Almeida, C. R. Chimie 5 (2002) 845-854

[4] G. S. Ofelt, J. Chemical Physics 17(3) (1962) 511-520.

[5] B.R. Judd, Physical Review 127(3) (1962) 750-761.

[6] G Lakshminarayana, J Qiu, MG Brik, IV Kityk, Journal of Physics: Condensed Matter 20 (33), 335106

[7] Daliang Zhao, Xvsheng Quiao, Xianping Fan, Minquan Wang, Physical B 395 (2007) 10-15.

[8] S. Tanabe, S. Todoroki, K. Hirao, N. Soga, J. Non-Cryst. Solids 122(1) (1990) 59.

[9] T. Miyakawa, D. L. Dexter, Phys. Rev. B 1(7) (1970) 2961-2969.

[10] A. Kumar, D. K. Rai, and S. B. Rai, Spectrochimica Acta Part A 58 (2002), 2115-2125.

[11] K. Binnemans, Bull. Soc. Chim. Belg. 105(12) (1996) 793-798.

[12] P. Babu and C. K. Jayasankar, Physics B 279 (2000) 262-281

[13] W. T. Carnall, P. R. Fields, and K. Rainak, J. Chemical Physics 49(10) (1968) 4450-4455.

14] R.Arifin and M. Rahim Bin Sahar, Solid state Science and Technology 10(1) (2008) 29-36.

[15] C. Goerller-Walrand and K. Binnemans, Handbook on physics and chemistry of rare earth, Chapter167, Spectral intensiries of f-f transitions, (1998), 101-264.

[16] R. Reisfeld, Structure Bonding 22 (1975) 123-175. 